\title{
TOTAL-DOSE RADIATION HARDNESS ASSURANCE FOR SPACE ELECTRONICS
}

\author{
Peter S. Winokur and Daniel M. Fleetwood \\ Sandia National Laboratories \\ P. O. Box 5800 , Division 2147 \\ Albuquerque, NM 87185-5800 \\ (505) $844-2150$
}

CAMERA READY MANUSCRIPT prepared for:

Eighth Symposium

on Space Nuclear Power Systems

Albuquerque, New Mexico

7-10 January 1991

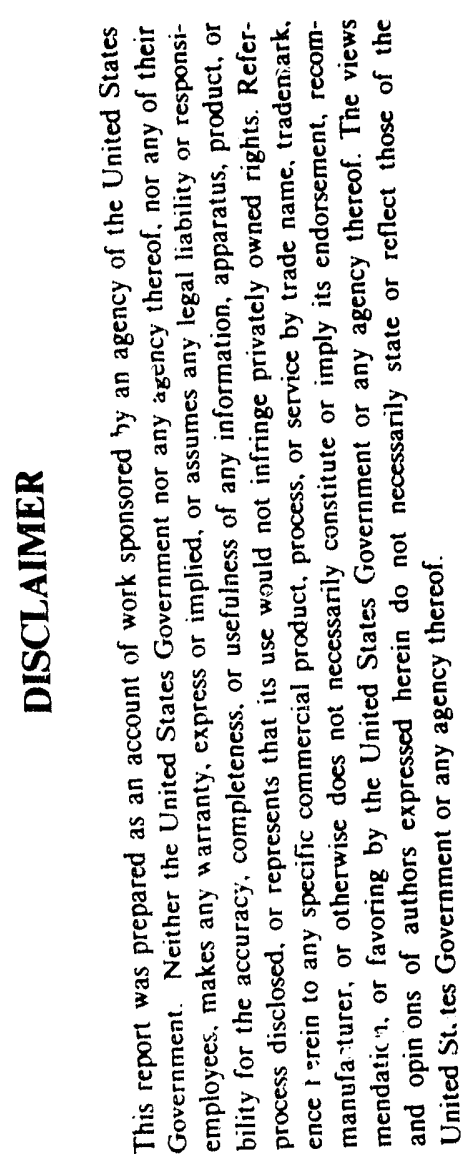

Author to whom correspondence should be sent: Daniel M. Fleetwood

This work was supported by the United States Department of Energy and the Defense Nuclear Agency.

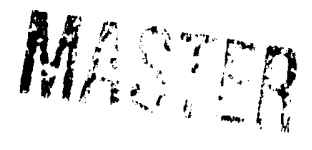


TOTAL-DOSE RADIATION HARDNESS ASSURANCE FOR SPACE ELECTRONICS

\author{
Peter S. Winokur and Daniel M. Fleetwood \\ Sandia National Laboratories \\ P. O. Box 5800 , Division 2147 \\ Albuquerque, NM 87185-5800 \\ (505) $844-: 150$
}

\begin{abstract}
An improved standard total-dose test method is described to qualify electronics for a lowdose-rate radiation environment typical of space systems. The method consists of ${ }^{60} \mathrm{Co}$ irradiation at a dose rate of $1-3 \mathrm{~Gy}(\mathrm{Si}) / \mathrm{s}(100-300 \mathrm{rad}(\mathrm{Si}) / \mathrm{s})$ and a subsequent $373 \mathrm{~K}\left(100^{\circ} \mathrm{C}\right)$ bake. New initiatives in radiation hardness assurance are also briefly discussed, 'cluding the Qualified $\mathrm{M}$-nufacturers List (QML) test methodology and the possible use of $1 / \mathrm{f}$ noise measurements is a nonc'estructive screen for oxide-trap charge related failure.
\end{abstract}

\title{
INTRODUCTION
}

The radiation response of complementary-metal-oxide-semiconductor (CMOS) electronics can depend strongly on the dose rate of the exposure and the postirradiation annealing time (Fleetwood et al. 1988). This has led some workers to suggest that the response of CMOS electronics at low dose rates is fundamentaily different than at higher rates (Goben et al. 1988). If this were the case, then hardness assurance testing for space application of CMOS electronics would have to be performed at dose rates closer to space $(<1 \mathrm{mGy}(\mathrm{Si}) / \mathrm{s})$ than presently specified, for example, in MIL-STD 883C, Method $1019(1-3 \mathrm{~Gy}(\mathrm{Si}) / \mathrm{s})$. This would place a large cost burden on space systems, because low dose rate testing can be very expensive, time consuming, and difficult to perform correctly (Fleetwood et al. 1988). However, recent studies have shown that the response of CMOS electronics to low-dose-rate irradiation can either be exactly reproduced, or conservatively estimated, by higher dose-rate irradiations followed by biased annealing (Fleetwood et al. 1988 and 1989). Based on this work, an alternative test has been proposed to qualify CMOS electronics for low-dose-rate radiation environments (Fleetwood et al. 1989). Below we summarize this method, and briefly discuss new initiatives in radiation hardness assurance.

\section{TOTAL DOSE TEST METHOD}

The test method consists of the following sequence:

(1) Irradiate the device or circuit in a ${ }^{69}$ Co source to 1.0 -times the exposure expected during the life of the system. under worst case bias conditions. The irradiation conditions and ine lot sample sizes are those defined in MIL-STD 883C. Method 1019 (Winokur et al. 1985 and Namenson 1988).

(2) Perform standard functional and parametric testing.

(3) If the devices pass $a_{1}$ i required tests in (2), irradiate the same sample of parts according io Method 1019 under the same biaj as in (1) to an additional 0.5-times the desired total dose, for a total exposuro of 1.5-times the system total-dose sperification.

(4) After the exposure in (3), remive the devices from the source and heat them under the bias of (1) and (3) to $373 \mathrm{~K}\left(100^{\circ} \mathrm{C}\right)$, and maintain bias and temperature continuously for ! 68 $(-0 /+24)$ hours. Then allow the devices to cool to the ambient test temperature under bias.

(5) Repeal the tests of (2). 
Steps (1) and (2) will eliminate devices that could fail in space due to the buildup of trapped positive charge in MOS insulators, and steps (3)-(5) will eliminate devices that could fail in space due to interface trap buildup. The technical basis of the proposed test method is discussed in more detail by Fleetwood et al. (1988 and 1989). We feel that this test method is more practical and economical than low-dose-rate testing. Moreover, it also provides a more stringent test of CMOS device hardness in space applications than low-dose-rate testing.

\section{NEW INITIATIVES IN RADIATION HARDNESS ASSURANCE}

\section{Qualified Manufacturers List (OML)}

The total-dose test method described above can be applied to any CMOS circuit or device, without prior knowledge of its detailed radiation response. This is within the "Qualified Parts List (QPL.)" test methodology. It has been recognized that, while effective, the QPL test methodology does not allow manufacturers to use the knowledge gained in developing and characterizing a technology to be employed to reduce the amount of testing required for radiation hardness assurance. Under the sponsorship of Rome Air Development Center and the Defense Electronics Supply Center, the United States Government has proposed a Qualified Manufacturers List (QML) methodology to qualify integrated circuits for applications requiring high reliability and radiation hardness. The details of this methodology are defined in military specification MIL-I-38535. Issues involved with applying MIL-I3.535 to qualify electronics for the space environment have been discussed recently by Winokur et al. (1990). These issues include statistical process control of technology parameters relevant to radiation hardness, test-structure to integrated-circuit response correlation, and extrapolation from laboratory test results to response in use environments. Addressing these issues is key to a cost-effective implementation of the QML test methodology, and thus to reducing testing expenses and increasing microcircuit quality (Winokur et al. 1990).

\section{Nondestructive Testing: $1 / f$ Noise}

Present hardness assurance test methods depend on irradiating and testing a small sample of the devices and circuits required for a space system. This incurs the risk that the devices flown may not exhibit the same hardness as those tested; in particular, the possibility of "maverick" chips that lie outside the main distribution of the hardness population cannot be excluded with this method. Recently, a strong correlation has been found between the preirradiation $1 / \mathrm{f}$ noise of MOS transistors and their postirradiation oxide-trap charge (Fleetwood and Scofield 1990). This suggests that $1 / \mathrm{f}$ noise measurements could be used as a $100 \%$ nondestructive screen for oxide-trap charge related failures in MOS transistors. Such a test might be very useful for low-earth orbit or other low-total-dose (less than about 100 $\mathrm{Gy}(\mathrm{Si})$ ) applications in which commercial (high-reliability, but non-radiation-hardened) electronics might be employed. Presently, this test can only be applied to discrete devices, or to small-scale circuits in which individual transistors can be isolated (Scofield et al. 1989). Still, this method appears to warrant follow-on study in the future to evaluate its applicability to radiation hardness assurance for space systems.

\section{CONCLUSIONS}

An improved procedure has been developed to qualify electronics for low-total-dose radiation exposure. This method can be used to decrease costs over low-dose-rate testing. New initiatives in radiation hardness assurance, the QML test methodology and $1 / \mathrm{f}$ noise, are being explored in an effort to further reduce testing time and cost, as well as to increase the quality and reliability of CMOS electronics for the space environment.

\section{Acknowledgments}

This work performed at Sandia National Laboratories was supported by the United States Department of Energy through Contract No. DE-AC04-76DP00789, and by the Defense 
Nuclear Agency through its hardness assurance program. We thank Fred Sexton, Jim Schwank, Marty Shaneyfelt, John Scofield, Paul Dressendorfer, Lew Cohn, and Harvey Eisen fn: stimulating discussions.

\section{References}

Fleetwood, D. M., P. S. Winokur, and J. R. Schwank (1988) "Using Laboratory X-ray and Cobalt-60 Irradiations to Predict CMOS Device Response in Strategic and Space Environments," IEEE Trans. Nucl. Sci. NS-35(6), 1497-1505.

Fleetwood, D. M., P. S. Winokur, L. C. Riewe, and R. L. Pease (1989) "An Improved Standard Total Dose Test for CMOS Space Electronics," IEEE Trans. Nucl. Sci. NS-36(6), 1963-1970.

Fleetwood, D. M. and J. H. Scofield (1990) "Evidence that Similar Point Defects Cause 1/f Noise and Radiation-Induced-Hole Trapping in Metal-Oxide-Semiconductor Transistors," Phys. Rev. Lett., 64(5), 579-582.

Goben, C. A. and W. E. Price (1988) Premature Failures at Low Dose Rates in SGS 4007 CMOS Devices, JPL D-5996, Rev. A.

Namenson, A. (1988), "Lot Uniformity and Small Sample Sizes in Hardness Assurance," IEEE Trans. Nucl. Sci. NS-35(6), 1506-1511.

Scofield, J. H., T. P. Doerr, and D. M. Fleetwood (1989), "Correlation Between Preirradiation 1/f Noise and Postirradiation Oxide-Trapped Charge in MOS Transistors," IEEE Trans. Nucl. Sci. NS-36(6), 1954-1961.

Winokur, P. S., F. W. Sexton, J. R. Schwank, D. M. Fleetwood, P. V. Dressendorfer, T. F. Wrobel, and D. C. Turpin, "Total Dose Radiation and Annealing Studies: Implications for Hardness Assurance Testing," IEEE Trans. Nucl. Sci. NS-33(6), 1343-1351.

Winokur, P. S., F. W. Sexton, D. M. Fleetwood, M. D. Terry, M. R. Shaneyfelt, P. V. Dressendorfer, and J. R. Schwank, "Implernenting QML for Radiation Hardness Assurance," IEEE Trans. Nucl. Sci. NS-37(6), 1806-1817. 

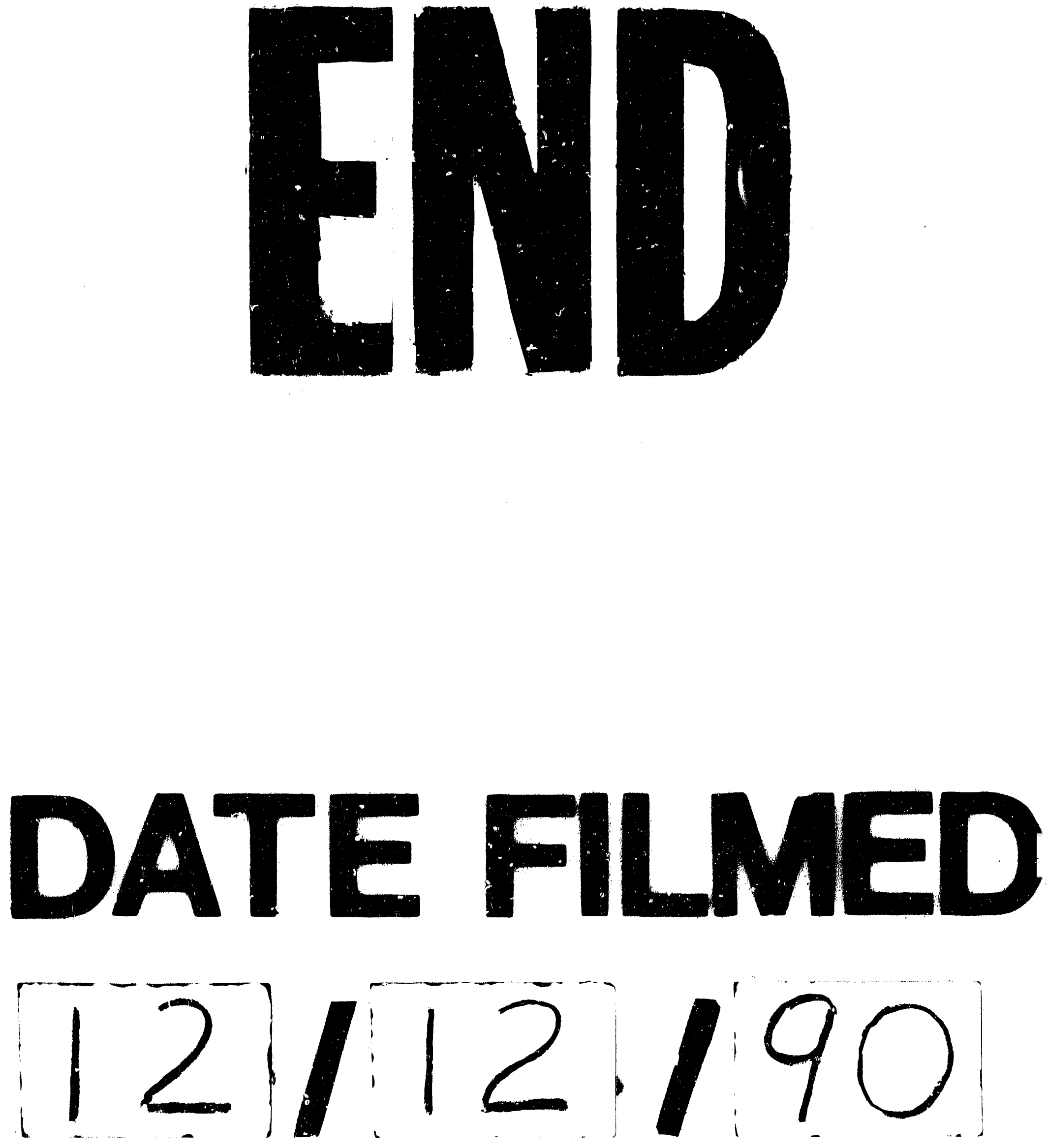
